\title{
Through Benevolent Eyes: the Differential Efficacy of Perspective Taking and Cognitive Reappraisal on the Regulation of Shame
}

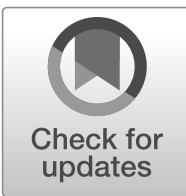

\section{Govind Krishnamoorthy ${ }^{1}$ (D) Penelope Davis ${ }^{2} \cdot$ Analise O'Donovan $^{2}$ • Brett McDermott ${ }^{3} \cdot$ Amy Mullens $^{1}$}

Published online: 1 September 2020

(C) Springer Nature Switzerland AG 2020

\begin{abstract}
Difficulties in regulating feelings of shame is a risk factor for the onset and recurrence of mental health disorders. The present research investigated the impact of the individual differences in propensity to experience shame (or shame-proneness) on two emotion regulation strategies - perspective taking and positive reappraisal. A total of 228 participants, undergraduate students, were allocated randomly to one of the eight experimental conditions. The results revealed that for high shame-prone participants, the use of perspective taking, without positive reappraisal, led to a heightened experience of shame. In contrast, the combination of perspective taking and positive reappraisal led to reductions in shame among high shame-prone participants. The findings highlight the relationship between individual differences, and the separate and combined effects of affect regulation strategies on the experience of shame.
\end{abstract}

Keywords Shame $\cdot$ Negative self-evaluations $\cdot$ Reappraisal $\cdot$ Perspective taking $\cdot$ Emotion regulation

\section{Introduction}

Individuals who have difficulty effectively managing negative emotional responses to daily life stressors may be at increased risk of developing mental health disorders such as depression (e.g. Sloan et al. 2017; Sheppes et al. 2015). Such findings have illuminated the need for a richer understanding of the emotional phenomenology of

Govind Krishnamoorthy

Govind.krishnamoorthy@usq.edu.au

1 University of Southern Queensland, 11 Salisbury Road, Ipswich, Queensland 4305, Australia

2 Griffith University, 176 Messines Ridge Road, Mount Gravatt, Queensland 4122, Australia

3 James Cook University, James Cook Drive, Douglas, Queensland 4814, Australia 
mental health conditions and investigations of the role of specific emotions. One emotion that has been the subject of extensive research is shame. Shame is commonly defined as an intense negative emotion characterized by the perception of a global devaluation of the self (Tangney and Dearing 2003). Shame has been conceptualized as being fundamentally different from other emotions, such as guilt, as it results from attributing information about a specific situation to characterological defects (e.g. a person feeling ashamed may think, 'I am bad') rather than to situational factors (e.g. a person feeling guilty may think, 'I did something bad') (Lewis 1987, p. 42).

The inability to regulate feelings of shame is a significant risk factor for the onset and recurrence of depression (Kim et al. 2011), anxiety (Fergus et al. 2010), suicide (Wiklander et al. 2012), post-traumatic stress disorder (Cunningham et al. 2019), addictions (Potter-Efron and Bruce 2014), eating disorders (Duarte and PintoGouveia 2017), personality disorders (Peters \& Geiger, 2016) and violent behaviour (Shanahan et al. 2011). With evidence on the role of shame in psychopathology accumulating, new research is focusing on ways individuals may more effectively regulate shame. Studies on the emotion regulation of shame have focused on those who are 'shame-prone'-individuals who experience shame on a frequent basis (Whittle et al. 2016; Stuewig et al. 2015; Tangney and Dearing 2003). 'Shame-proneness' has been conceptualized as a dispositional trait (as opposed to an experience or state) and shame has been shown to be a pervasive aspect of the identities of shame-prone individuals (Tangney and Dearing 2003). Theories on the links between shame and psychopathology have focused on the ways in which the emotion regulation strategies of perspective taking and positive reappraisal have mitigated the effects of shame (Webb et al. 2012).

\section{Perspective Taking}

Perspective taking, also referred to in the literature as self-distancing ${ }^{1}$, is an emotion regulation strategy wherein individuals adopt an external perspective and thus 'think about themselves as an object of attention' (Kross and Ayduk 2017). Recalling and thinking about experiences of anger and sadness from a third-person perspective has been found to lead to a attenuation of negative emotions, compared to taking a firstperson perspective, which often leads to more ruminative styles of thinking (Kross and Ayduk 2008; Kross, Ayduk \& Mischel, 2005). For example, in a series of experimental studies, Libby et al. (2005) manipulated the memory perspective (first-person vs. thirdperson) that individuals used to visually recall autobiographical events and examined its effects on assessments of personal change in psychotherapy. The results revealed that participants told to recall their first appointment from the third-person perspective thought they had changed more than those told to recall the event from the first-person perceptive. Thus, the authors concluded that recalling significant autobiographical events from different visual perspectives led to different judgements over time. In their meta-analysis, Webb et al. (2012) identified perspective taking as one of the most effective techniques for facilitating emotion regulation.

\footnotetext{
${ }^{1}$ Given the current public health recommendations around physical distancing in light of COVID-19, the term 'perspective taking' has been used over 'self-distancing' to avoid confusion.
} 
Such findings are consistent with work on mindfulness and meditation (Brown and Ryan 2003; Kabat-Zinn et al. 1992) and perspective taking is reflected in therapeutic approaches that encourage people to consider negative feelings and experiences from diverse perspectives (Linehan 1993; Teasdale et al. 2000). While much research points to the benefits of such perspective taking, several theorists have argued that perspective taking on its own may not have the same benefits in regulating shame as when coupled with positive reappraisal (e.g. Robinson and Swanson 1993).

\section{Positive Reappraisal}

Positive reappraisal, also referred to as cognitive reappraisal, is another cognitive coping strategy in which negative life events are actively recast in a more positive light (e.g. Lazarus and Folkman 1984; Gross, 1998). Thinking about the 'good that can come from a stressful event' is consistent with notion of positive reappraisal as involving a positive interpretation of a situation, or 'finding the silver lining' (Levine et al. 2012). Positive reappraisal has been found to be effective for regulating affect and physiological arousal without the costs, such as increased negative affect, associated with other strategies such as rumination (Gross, 1998). Positive reappraisal also has longer-lasting effects than attention-focused strategies (e.g. distraction) (Ochsner et al. 2012; Silvers et al. 2015) and is a core component of several therapeutic modalities, including cognitive behavioural therapy (Beck 2005). A number of studies have found positive reappraisal to be beneficial for both mental and physical health outcomes (Penley et al. 2002).

The ability to positively reappraise may be particularly salient for regulation of shame, as the experience of shame is often linked to ruminative cognitions with internal, stable, and uncontrollable attributions (e.g. thinking 'I'm dumb' in response to failure) (Tracy et al. 2007). In particular, this cognitive style has been linked to shame-proneness and has been found to be independently associated with depression, beyond the effects of a depressogenic attributional style (Tangney et al. 1992). Although no studies identified to date have assessed the impact of shame-proneness on positive reappraisal, several studies have found that experimentally induced positive reappraisal leads to a reduction in reports of negative emotions in both clinical and nonclinical samples (e.g. Ehring et al. 2010; Rood et al. 2012). However, some studies have found that individuals scoring high on indicators of neuroticism (Jylhä \& Isometsä, 2006) — characterized by proneness to anxiety, emotional instability and self-consciousness - have difficulty reappraising negative emotions.

Similarly, individuals identified as having a self-critical cognitive style-similar to those who are highly shame-prone - are seen as being less responsive to cognitive interventions (e.g. Castilho et al. 2017). Such research highlights that those who are shame prone have difficulty with using and benefiting from positive reappraisal. The findings also raise concerns about whether the efficacy of such cognitive intervention can be enhanced by the combined use of shame mitigation strategies. Interventions aimed at promoting the benefits of perspective taking while preventing self-critical cognition - particularly among shame-prone individuals - have led to the development of therapeutic techniques such as self-compassion (Neff 2003; Gilbert, 2010). While several studies on such practices have reported beneficial effects for shame-prone individuals (e.g. Woods and Proeve 2014; Mosewich et al. 2011), few experimental 
studies to date have investigated the unique contributions of positive reappraisal and perspective taking to attenuation of shame in such interventions.

Katzir and Eyal (2013) evaluated the efficacy of perspective taking and positive reappraisal on the experience of shame and other emotions (e.g. guilt, anger and sadness). Two hundred forty-eight university students completed the experiment individually, guided by pre-recorded audio instructions adapted from Kross et al. (2005). It was predicted that due to the experience of shame involving self-evaluation as well as the evaluation of the self from the perspective of others, a third-person perspective may exacerbate these emotions and fail to attenuate the experience of shame. The results revealed that while a third-person perspective attenuated feelings of sadness and anger, such benefits were not replicated for feelings of shame. In particular, Katzir and Eyal (2013) found that participants who adopted the perspective of a third-person, neutral observer when thinking about a shameful event failed to experience any attenuation in their experience of shame. They argued that perspective taking not accompanied by positive reappraisal leads to an increase in self-critical evaluations and rumination on others' negative evaluations of them (Katzir and Eyal 2013). Katzir and Eyal's (2013) study is significant as it illustrates the differential efficacy of perspective taking on the regulation of self-conscious emotions like shame, compared to other emotions like fear. The study also highlights the need for a further understanding of the individual differences that influence the combined and separate effects of these emotion regulation strategies on shame.

In summary, evidence suggests that shame plays a unique role in the development and maintenance of psychopathology. Despite the burgeoning literature on the efficacy of various emotion regulation strategies on negative affect, there have been limited investigations to date into the specific effects of these strategies on shame. Namely, there appears to be a paucity of studies regarding efficacious strategies for individuals who are prone to experiencing shame and may therefore be more vulnerable to developing various forms of psychopathology. Thus, the present study aims to extend Katzir and Eyal's (2013) research by evaluating the specific and combined effects of two promising emotion regulation strategies, positive reappraisal and perspective taking, on the regulation of feelings of shame experienced by individuals differing in shame-proneness.

\section{The Present Study}

This experimental study was designed to examine how different forms of positive reappraisal and perspective taking influence the regulation of shame following a mood induction task that involves recalling a shameful autobiographical event. To understand whether the effects of the emotion regulation strategies are specific to shame, the influence of these strategies on other negative emotions (anger, anxiety, sadness, guilt and disgust) and positive emotions (happiness, pride, hope, amusement and affection) were also measured.

Based on previous experimental research, we developed the following hypotheses.

Hypothesis 1: Participants instructed to engage in positive reappraisal of an autobiographical event in which they felt shame (condition: positive reappraisal) report lower levels of shame compared to participants instructed to focus on 
aspects of the event that initially made them feel and respond negatively (not encouraged to reframe the event positively; condition: no positive reappraisal).

Hypothesis 2: Among low shame-prone participants, those instructed to adopt a third-person perspective report lower levels of shame compared to participants asked to adopt a first-person perspective (i.e. low shame-prone participants will benefit from the purported benefits of a third-person perspective).

Hypothesis 3: Low shame-prone participants asked to adopt a third-person perspective, together with positive reappraisal, report the lowest levels of shame.

Hypothesis 4: Among high shame-prone participants, those instructed to adopt a third-person perspective report the same levels of shame as participants asked to adopt a first-person perspective (i.e. high shame-prone participants do not benefit from taking a third-person perspective).

Hypothesis 5: Participants with a high propensity to experience shame (high shame-prone) report higher levels of shame compared to participants with a low propensity to experience shame (low shame-prone) when recalling an autobiographical, shame-eliciting event, irrespective of the memory perspective adopted or the use of positive reappraisal.

Together these hypotheses lead to the prediction of a three-way interaction between shame-proneness, positive reappraisal and perspective taking in the manipulation phase of the study. These variables may also interact in other ways to influence the outcome. However, no compelling theoretical or empirical grounds exist for the ad hoc prediction of additional interactions and no firm predictions were made concerning them.

\section{Method}

We report how we determined the sample size, all manipulations, all exclusions and all measures in the study. Ethics approval to conduct the study was received from the Griffith University Human Research Ethics Committee (Reference Number: PSY/03/ 08/HREC). This research did not receive any specific grant from funding agencies in the public, commercial or not-for-profit sectors. On behalf of all authors, the corresponding author states that there is no conflict of interest.

\section{Participants}

Study participants were 228 undergraduate students (46 males, 182 females) ranging in age from 16 to 51 years (mean age 20.99 years, SD 6.37 years). Consistent with other experimental studies investigating the impact of positive reappraisal (Ray et al. 2008) and perspective taking (Libby \& Eibach, 2002) in non-clinical populations, the aim was to recruit 20 participants in each of the eight experimental conditions, with a minimum of 10 per condition. This sample size was determined in order to detect effect sizes of $d \geq .20$ with statistical power equal to 0.80 at significance level 0.05 . Participants were from Griffith University in Australia and were recruited via an advertisement on the university's research participation website. The online advertisement described the study as an investigation into individual differences in the recall of emotional events. 
All participants were introductory psychology students who were given credit toward their course grade.

\section{Measures}

Shame-proneness: Test of Self-Conscious Affect-3 (TOSCA-3) The Test of SelfConscious Affect (TOSCA; Tangney, et al., 1989) measures proneness to shame and guilt and has been used extensively in studies of shame (e.g. Ferguson \& Crowley, 1997; Quiles \& Bybee, 1997). The TOSCA is a scenario-based measure in which 15 common situations are posed to respondents, followed by descriptions of shame, guilt and other emotional (e.g. alpha and beta pride) and defensive (e.g. externalization and detachment) responses to the situation, without use of emotion labels. The TOSCA has demonstrated good internal consistency for shame-proneness and guilt-proneness (Cronbach's $\alpha=.76$ and .66, respectively; Tangney, 1990, 1991; Tangney et al., 1996). In our sample, internal consistency for TOSCA was satisfactory with Cronbach's $\alpha=0.74$. Participants were divided into groups of 'high shame-proneness' and 'low shame-proneness' based on a median split of shame-proneness scores - with 12 participants with median shame-proneness scores excluded from the groups.

Affective states: visual analogue scales (VAS) Participants were asked to rate the extent to which they experienced 11 emotions (anger, happiness, anxiety, pride, sadness, shame, hope, guilt, amusement, disgust and affection) during the six experimental phases on a Likert rating scale from 1 (not at all) to 10 (extremely).

\section{Procedure}

The study adapted Katzir and Eyal's (2013) experimental method to investigate participants' experiences of shame. Figure 1 depicts the experimental phases of the study. The eight groups correspond to combinations of the two forms of perspective taking (first-person perspective, third-person perspective; 'Perspective' hereafter), the two positive reappraisal styles (positive reappraisal, no positive reappraisal; 'Appraisal' hereafter) and the two levels of shame-proneness (high shame-proneness, low shameproneness; 'Shame-proneness' hereafter).

In the baseline phase, participants were asked to rate their current affective state with the visual analogue scales (VAS) with respect to 11 emotions (anger, happiness, anxiety, pride, sadness, shame, hope, guilt, amusement, disgust and affection) (Fig. 1). In the second phase, mood induction, participants were asked to identify a recent, unresolved event that had generated feelings of shame. The participants were provided with brief descriptions of typical shame-inducing events and emotional reactions to shame-inducing events to help them recall shame events. When an experience came to mind, the participants were asked to write down a detailed description of the memory in the response booklet provided (phase: free recall (shame event); Fig. 1). The participants were given 5 min to recall and describe the memory.

Participants then rated the emotions they experienced both during (or soon after) the shame event and in the present, when they recalled the experience at the present time. They were also asked how long ago the event occurred and to rate the extent to which 


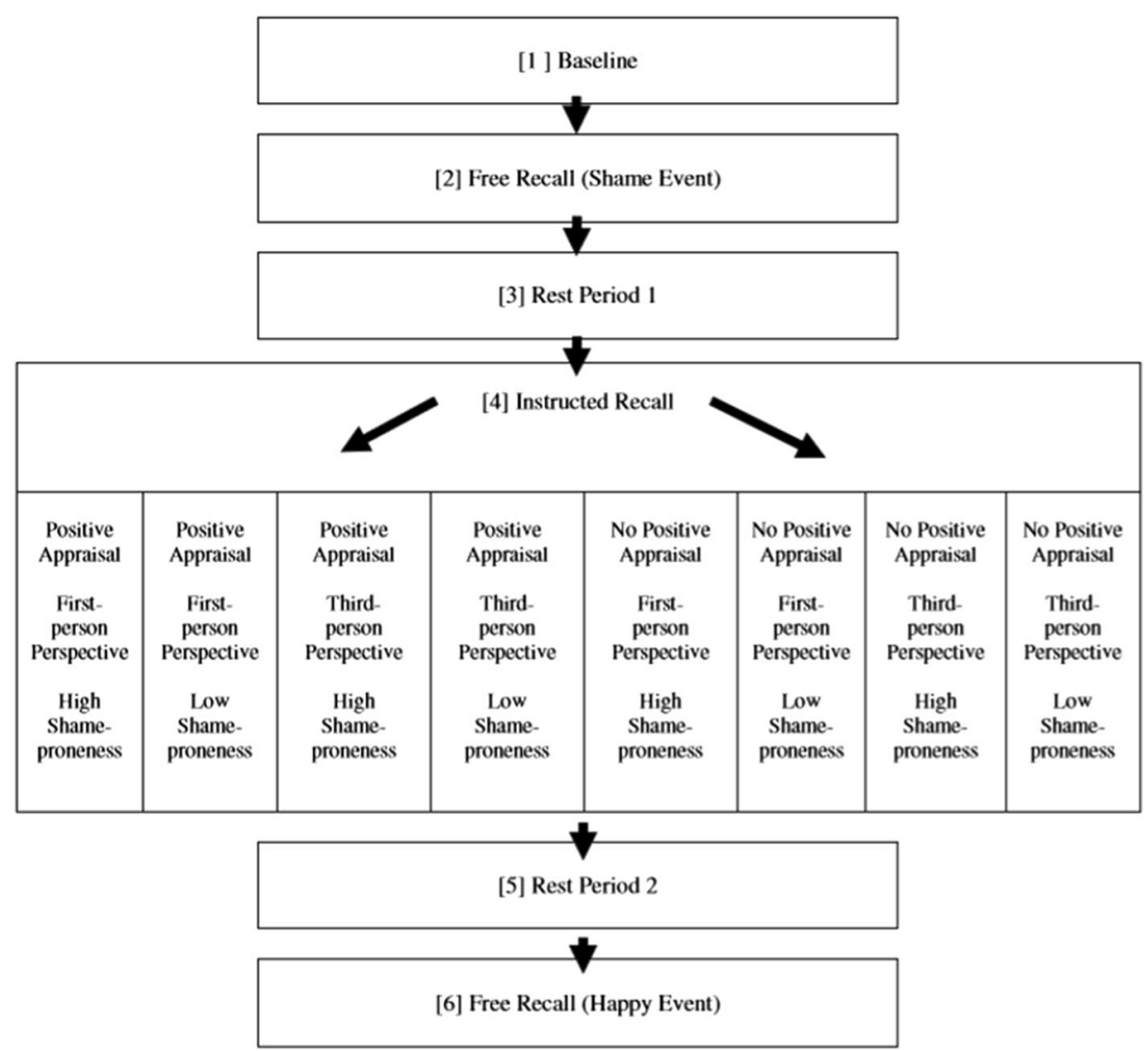

Fig. 1 Flow chart of the experimental phases of the study. Numbers in the parentheses indicate chronological sequence of data collection

they thought about the event both from a first-person perspective and from a thirdperson perspective (Appendix). These ratings were made using a 5-point scale ( $0=$ not at all, $4=\mathrm{a}$ lot). Following this, participants were instructed to rest quietly for $2 \mathrm{~min}$ (phase: rest period 1; Fig. 1). No other specific instructions were provided to the participants during this phase. After the rest period, the participants once again rated their emotions on the 10-point VAS. They were also asked to rate the extent to which they had thought about the shame event in the rest period on a scale of $0 \%$ (did not think about the event at all during the rest period) to $100 \%$ (thought about the event during the entire rest period). If the participants did think about the event, they were asked to rate the extent to which they thought about it from a first-person perspective and from a third-person perspective.

Participants were then allocated randomly to one of the eight experimental conditions. In each of the conditions, participants were asked to think about their recalled shame event again. Participants were given specific instructions on aspects of the event to focus on, depending on the experimental condition they were allocated to (i.e. firstor third-person perspective; positive reappraisal or no positive reappraisal; see Appendix for instructions provided to groups). Instructions relating to positive reappraisal of 
the recalled shame event were adapted from those used by Ray et al. (2008). Instructions relating to perspective-taking were adapted from Libby et al. (2005).

Participants were then asked to follow these instructions for $2 \mathrm{~min}$ (phase: instructed recall) (Fig. 1). At the end of this instructed recall task, participants were once again asked to rate their emotions on the VAS. They were also asked to report their compliance with the instructions by rating the extent to which they thought about the event from their own perspective and from another person's perspective, and the total amount of time during the task they spent thinking about the shame event. Participants were then given $5 \mathrm{~min}$ to answer the five questions posed to them during the instructed recall task (e.g. Can you see whether you are standing or sitting?) and describe what and how they thought about the shame event during the instructed recall task.

Following this, participants were asked to rest quietly for $2 \mathrm{~min}$ (phase: rest period 2) (Fig. 1). They were then once again asked to rate their emotions, the extent to which they thought about the shame event during the rest period, and the extent to which they thought about the shame event from their own perspective and from another person's perspective. Participants were then asked to recall and describe a recent experience of feeling happy for $3 \mathrm{~min}$ (phase: free recall (happy event)) (Fig. 1). This phase was included in the study in order to provide participants with an opportunity to recover from the experience of negative emotions and finish the study feeling less distressed. After describing their happy event, participants were asked to rate their emotions on the rating scale. Finally, participants were asked to complete the Test of Self-Conscious Affect (TOSCA).

\section{Results}

\section{Preliminary Analyses}

A 2 (Appraisal) $\times 2$ (Perspective) $\times 2$ (Shame-proneness) analysis of variance (ANOVA) conducted on age revealed a main effect for Appraisal, $F(1,206)=5.39$, $\eta 2=0.02, p<0.05$. The means for Appraisal revealed that participants in the positive reappraisal groups $(M=22.03, \mathrm{SE}=0.63)$ were significantly older than participants in the no positive reappraisal groups $(M=19.96, \mathrm{SE}=0.62)$. Given this difference, participant age was controlled for in final analyses.

A series of 2 (Appraisal) $\times 2$ (Perspective) $\times 2$ (Shame-proneness) ANOVAs were also conducted on the various characteristics of the shame event recalled. The means and standard deviations for attributes of the shame events are presented in Table 1. The ANOVAs revealed no significant group differences for these variables. The average intensity of shame experienced during the recalled shame event was high $(M=7.92$, $\mathrm{SE}=2.08$ ).

A significant main effect was found for shame-proneness in rest period $1, F(1$, $206)=5.22, \eta 2=0.02, p<0.05$, and rest period $2, F(1,206)=6.92, \eta 2=0.03$, $p<0.01$. A comparison of group means revealed that during both rest periods, participants in high shame-proneness groups $\left(M_{\text {Rest Period 1 }}=4.19, \mathrm{SE}=0.32 ; M_{\text {Rest Period 2 }}=\right.$ $4.19, \mathrm{SE}=0.35)$ reported having thought about the shame event more often than participants in low shame-proneness groups $\left(M_{\text {Rest Period 1 }}=3.23, \mathrm{SE}=0.26 ; M_{\text {Rest Period }}\right.$ 
Table 1 Means (with standard deviation in parenthesis) for ratings of shame for the eight groups as a Function of Appraisal, Perspective and Shame-Proneness

Phase

\begin{tabular}{|c|c|c|c|c|c|c|c|}
\hline Condition & $N$ & Baseline & $\begin{array}{l}\text { Free recall } \\
\text { (shame event) }\end{array}$ & $\begin{array}{l}\mathrm{R} \text { e } \mathrm{s} \mathrm{t} \\
\text { period } 1\end{array}$ & $\begin{array}{l}\text { Instructed } \\
\text { recall }\end{array}$ & $\begin{array}{l}\mathrm{R} \text { e } \mathrm{s} \mathrm{t} \\
\text { period } 2\end{array}$ & $\begin{array}{l}\text { Free recall Mean } \\
\text { (happy event) }\end{array}$ \\
\hline
\end{tabular}

First-person perspective

Positive appraisal

Low

shame-proneness 31 1.163.802.352.962.251.352.31(0.37)(2.35)(1.79)(1.76)(1.61)(0.83)(0.98) High shame-proneness202.004.253.103.803.051.502.95(1.68)(2.73)(2.44)(2.16)(1.98)(1.14)(1.04)Mean1.493.932.64 3.292.561.41(1.15)(2.49)(2.08)(1.95)(1.79)(0.96) No positive appraisal Low shame-proneness 281.423 .42 1.964.922.211.212.25(0.92)(2.02)(1.07)(3.16)(1.49)(0.49)(1.40) High shame-proneness261.724.723.244.64 4.241.963.42(1.40)(2.92)(2.63)(3.52)(3.40)(1.67)(1.33)Mean1.564.032.564.793.161.56(1.16)(2.54)(2.05)(3.30) (2.75)(1.24)Third-person perspective Positive appraisal Low shame-proneness381.283.472.282.522.131.31 2.16(0.89)(2.35)(1.27)(1.82)(1.57)(0.70)(0.81) High shame-proneness 191.315.423.002.893.361.942.98 $(1.15)(2.83)(2.38)(1.52)(2.54)(1.47) 1.41 \quad$ Mean1.294.122.522.642.541.52(0.98)(2.66)(1.73)(1.72)(2.01) (1.05) No positive appraisal Low shame-proneness321.584.292.514.322.541.412.77(1.43)(2.47)(1.92) $(2.67)(2.04)(0.71)(1.27) \quad$ High shame-proneness221.905.594.097.093.952.454.17(1.50)(2.82)(2.70)(2.52) (2.75)(1.96)(1.93) Mean1.714.833.165.473.131.84(1.45)(2.67)(2.39)(2.93)(2.44)(1.45)Shame-proneness was ascertained using participant scores on the Test of Self-Conscious Affect (TOSCA) (Tangney et al., 1989). Ratings of affective states were obtained using a 10-point visual analogue scale (VAS) Likert rating scale. Twelve participants with median shame-proneness scores were excluded from the groups as participants were divided into high and low shame-proneness groups based on a median split of shame-proneness scores

${ }_{2}=2.98, \mathrm{SE}=0.29$ ). Since thinking about the shame event during Rest Period 1 may influence performance during the instructed recall phase, this was controlled for in subsequent analyses.

A main effect was also found for Perspective in the instructed recall phase, $F$ (1, $206)=8.14, \eta 2=0.03, p<0.01$. The means for Perspective revealed that participants in the third-person perspective groups $(M=6.84, \mathrm{SE}=0.28)$ thought about the shame event for a significantly longer time during the instructed recall phase compared to participants assigned to the first-person perspective $(M=5.68, \mathrm{SE}=0.28)$ groups. This difference was controlled for in final analyses.

\section{Main Analyses}

\section{Shame}

Data were analysed with a 2 (Perspective) $\times 2$ (Appraisal) $\times 2$ (Shame-Proneness) $\times 6$ (Phase) factorial analysis of covariance (ANCOVA) with repeated measures on the fourth factor. Covariates were age, ratings of the frequency of thinking about the shame event during rest period 1, and frequency of thinking about the shame event during instructed recall. Checks for normality of the data revealed that skewness ranged from mild to moderate, with the greatest skewness found on ratings of shame at baseline and during the free recall (happy event) phase. The other variables displayed modestly elevated levels of skewness $(x>0.03)$ and kurtosis $(x>3)$. ANCOVA is robust to small 
departures from normality and analyses were performed on untransformed data (Tabachnick \& Fidell, 2007).

The Phase variable violated the homoskedasticity assumption for the ANCOVA (Mauchly's test of sphericity $p<0.001$ ) and a Greenhouse Geisser correction was applied. Post hoc $t$ tests were conducted for pair-wise comparisons, with the Bonferroni correction used for multiple comparisons. Descriptive statistics for the dependent measures are presented in Table 1 . To elucidate more clearly the pattern of results captured by the four-way interaction, the data are portrayed in Fig. 2.

A main effect was found for Appraisal, $F(1,203)=11.73, \eta 2=0.05, p<0.01$. The means for Appraisal revealed that, overall, the no positive reappraisal groups $(M=3.22$, $\mathrm{SE}=0.13)$ reported higher levels of shame than the positive reappraisal groups $(M=$ 2.56, $\mathrm{SE}=0.13)$. A main effect was found for Shame-proneness, $F(1,203)=16.42$, $\eta 2=0.07, p<0.001)$ : As expected, high shame-proneness groups $(M=3.28, \mathrm{SE}=$ $0.14)$ reported higher ratings of shame than low shame-proneness groups $(M=2.50$, $\mathrm{SE}=0.12)$. A main effect was also found for Phase, $F(3.72,203)=10.57, \eta 2=0.05$, $p<0.001$. Post hoc analyses of the means for Phase revealed that shame ratings during the free recall (shame event) phase $(M=4.34, \mathrm{SE}=0.16)$ and the instructed recall phase $(M=4.12, \mathrm{SE}=0.16)$ were higher than during the two rest periods $\left(M_{\text {Rest Period } 1}=2.78\right.$, $\mathrm{SE}=0.12 ; M_{\text {Rest Period } 2}=2.94, \mathrm{SE}=0.14 ; p$ 's $\left.<0.05\right)$. In turn, shame ratings in the rest periods were higher than ratings at Baseline $(M=1.54, \mathrm{SE}=0.08)$ and during free recall (happy event) $(M=1.63, \mathrm{SE}=0.08, p$ 's $<0.05)$. These main effects were qualified, however, by two significant interactions.

An interaction was revealed between Phase and Appraisal, $F(3.72,203)=11.63$, $\eta 2=0.05, p<0.001$. As depicted in Fig. 3, participants in the no positive reappraisal groups reported higher ratings of shame compared to the positive reappraisal groups

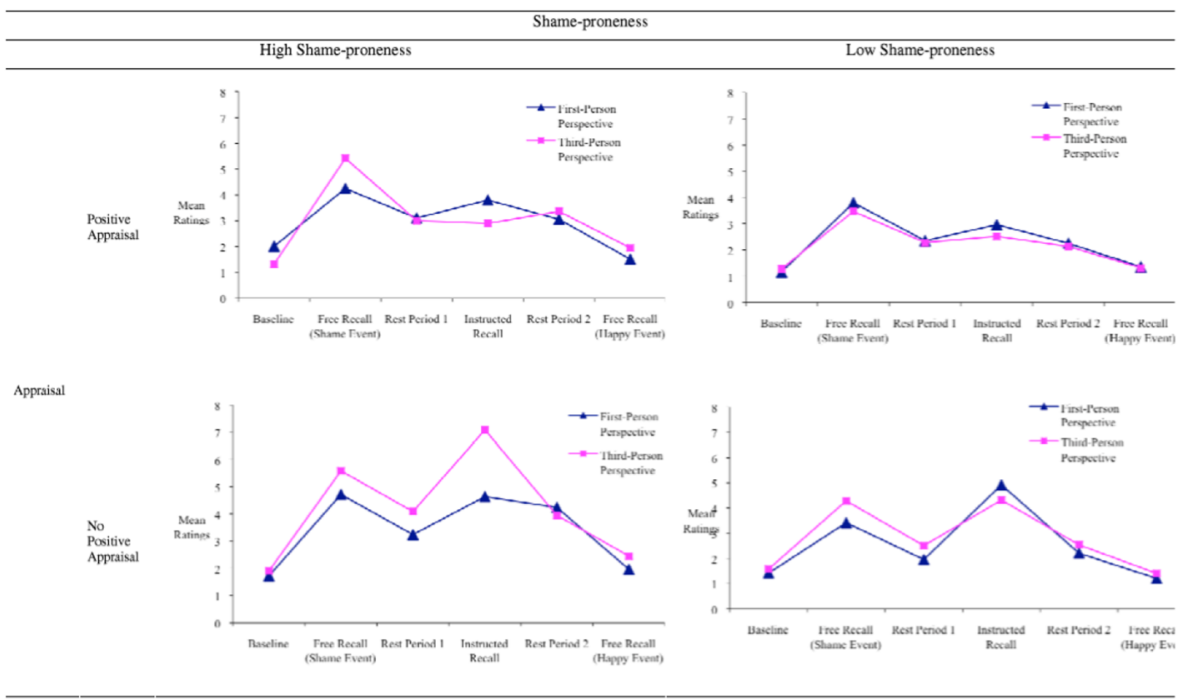

Fig. 2 Mean ratings for high and low shame-proneness, positive and no positive reappraisal groups across the six experimental phases. Shame-proneness was ascertained using participant scores on the Test of SelfConscious Affect (TOSCA) (Tangney et al., 1989). Ratings of affective states were obtained using a 10point visual analogue scale (VAS) Likert rating scale 
during instructed recall $\left(M_{\text {No positive reappraisal }}=5.18, \mathrm{SE}=0.23 ; M_{\text {positive reappraisal }}=3.05\right.$, $\mathrm{SE}=0.24 ; t=6.94, p<0.001)$ and rest period $2\left(M_{\text {No positive reappraisal }}=3.14, \mathrm{SE}=0.20\right.$; $\left.M_{\text {positive reappraisal }}=2.55, \mathrm{SE}=0.21 ; t=2.18, p<0.05\right)$.

\section{Hypothesis 1: Impact of Positive Reappraisal on the Experience of Shame}

Reliable differences between the positive reappraisal and no positive reappraisal groups were found for ratings of shame across each of the six phases. Participants in the no positive reappraisal groups reported significantly higher ratings of shame in the instructed recall phase $(M=5.18, \mathrm{SE}=0.23)$ than in the free recall (shame event) phase $(M=4.53, \mathrm{SE}=0.23 ; t=2.81, p<0.01)$. In contrast, participants in the positive reappraisal group reported significantly lower levels of shame in the instructed recall phase $(M=3.05, \mathrm{SE}=0.24)$ than in the free recall (shame event) phase $(M=4.14, \mathrm{SE}=0.24$; $t=5.09, p<0.001)$. Both the positive reappraisal and no positive reappraisal groups reported significantly lower levels of shame during rest period $2\left(M_{\text {No positive reappraisal }}=\right.$ $\left.3.23, \mathrm{SE}=0.20 ; M_{\text {positive reappraisal }}=2.66, \mathrm{SE}=0.21\right)$ than during instructed recall $\left(M_{\mathrm{No}}\right.$ positive reappraisal $=5.18, \mathrm{SE}=0.23 ; M_{\text {positive reappraisal }}=3.05, \mathrm{SE}=0.24 ; t_{\text {No positive reappraisal }}=$ $7.56, p<0.001 ; t_{\text {positive reappraisal }}=2.13, p<0.05$; Fig. 3 ). Thus, the first hypothesis predicting lower levels of shame in the positive appraisal condition than in the no positive appraisal condition was supported for low shame individuals but was only upheld for the high-shame groups adopting a third-person perspective (see Table 1). No

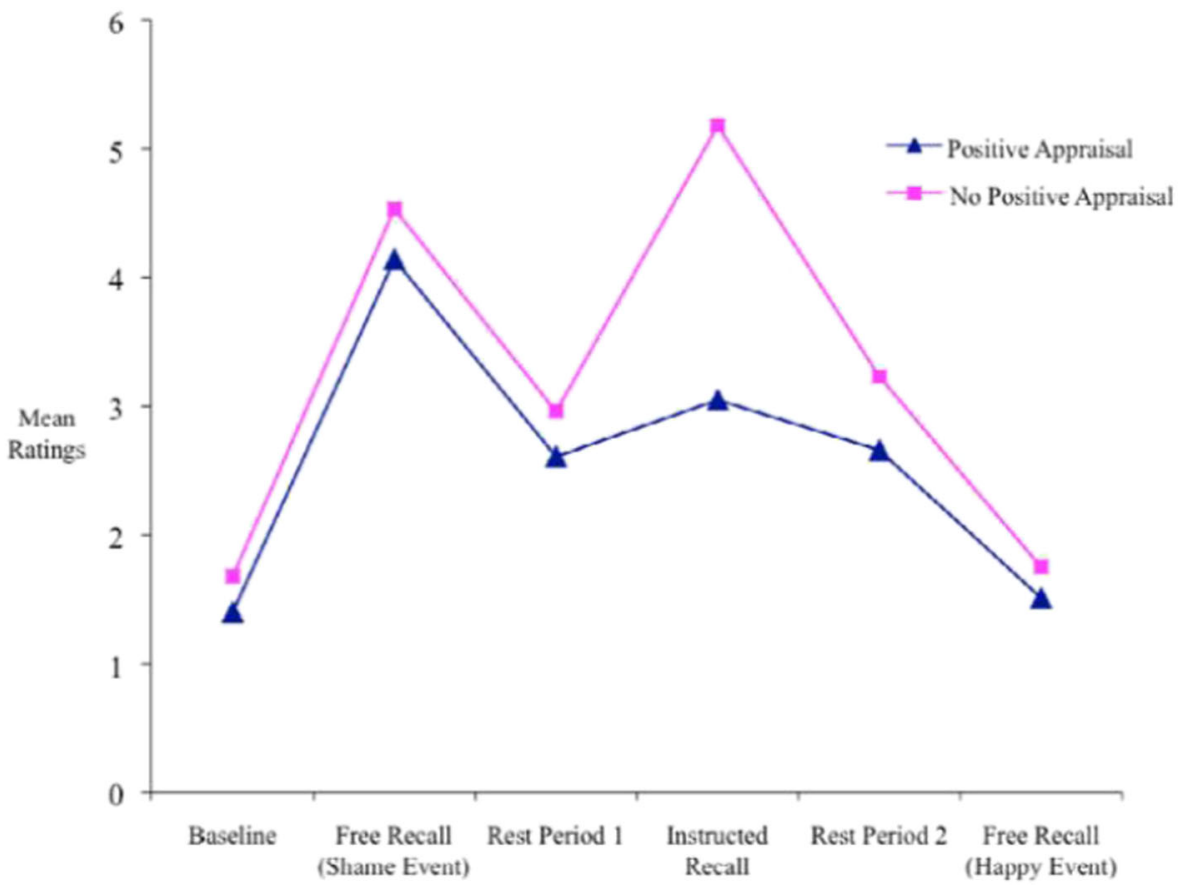

Fig. 3 The means of ratings of shame for the positive and no positive reappraisal groups across the six experimental phases 
reliable difference between the appraisal conditions appeared when high-shame individuals viewed the shame event from a first-person perspective.

\section{Hypothesis 2 and 3: The Combined and Separate Effects of Perspective and Appraisal on the Experience of Shame Among Low Shame-Prone Participants}

As depicted in Table 2, a significant main effect was found for shame-proneness across all the experimental phases except baseline, with low shame-prone groups reporting lower levels of shame than high shame-prone groups. The main effect for Appraisal during the instructed recall phase was found to be due to positive reappraisal groups reporting lower levels of shame than the no positive reappraisal groups. Of greater interest, however, is that the significant interaction between Appraisal, Perspective and Shame-proneness was found only for the instructed recall phase of the experiment, $F$ $(1,203)=7.62, \eta 2=0.03, p<0.01$ (see Table 2).

In the interest of facilitating understanding of this three-way interaction, two separate 2 (Perspective) $\times 2$ (Appraisal) ANCOVAs were conducted to assess the effects of Appraisal and Perspective on the high and low shame-proneness groups. Figure 4 depicts the Appraisal and Perspective results for the high and low shame-proneness groups. As expected, a significant main effect for Appraisal was found for both the high shame-proneness and low shame-proneness groups, with positive reappraisal groups reporting lower levels of shame than the no positive reappraisal groups. However, the interaction between Appraisal and Perspective for low shame-proneness group was not significant, $F(1,79)=3.62, \eta 2=0.10, p=0.06$. Thus, the second hypothesis was not supported, as no differences were found between the first- and third-person

Table 2 Analyses of covariance on Appraisal, Perspective and Shame-proneness for ratings of shame during the six experimental phases

\begin{tabular}{|c|c|c|c|c|c|c|}
\hline Source & $\begin{array}{r}F \\
\text { baseline }\end{array}$ & $\begin{array}{l}F \text { free recall } \\
\text { (shame event) }\end{array}$ & $\begin{array}{l}F \text { rest } \\
\text { period } 1\end{array}$ & $\begin{array}{l}\qquad F \\
\text { instructed } \\
\text { recall }\end{array}$ & $\begin{array}{l}F \text { rest } \\
\text { period } 2\end{array}$ & $\begin{array}{l}F \text { free recall } \\
\text { (happy event) }\end{array}$ \\
\hline Appraisal & 2.65 & 1.25 & 1.68 & $38.19 * * *$ & 3.59 & 2.28 \\
\hline Perspective & 0.50 & 2.28 & 0.83 & 0.19 & 0.00 & 1.88 \\
\hline Shame-proneness & 3.49 & $8.19 * *$ & $10.20 * *$ & $5.14^{*}$ & $15.59 * * *$ & $12.05^{* *}$ \\
\hline Age & 0.42 & 0.02 & 0.00 & 2.44 & 0.19 & 1.54 \\
\hline $\begin{array}{l}\text { Thoughts about the shame } \\
\text { event during rest period } 1\end{array}$ & 2.89 & $28.09 * * *$ & $43.19 * * *$ & $9.92 * *$ & $18.50 * * *$ & $7.02 * *$ \\
\hline $\begin{array}{l}\text { Thoughts about the shame } \\
\text { event during instructed } \\
\text { recall }\end{array}$ & 1.11 & 0.37 & 2.79 & 2.17 & 2.18 & 0.63 \\
\hline Appraisal $\times$ Perspective & 1.50 & 0.03 & 0.82 & 3.96 & 0.28 & 0.03 \\
\hline Appraisal $\times$ Shame-proneness & 0.08 & 0.26 & 3.31 & 1.48 & 2.26 & 3.12 \\
\hline $\begin{array}{l}\text { Perspective } \times \\
\text { Shame-proneness }\end{array}$ & 1.44 & 0.96 & 0.02 & 2.75 & 0.08 & 0.73 \\
\hline $\begin{array}{l}\text { Appraisal } \times \text { Perspective } \times \\
\text { Shame-proneness }\end{array}$ & 0.84 & 1.96 & 0.00 & $7.62 * *$ & 0.95 & 0.13 \\
\hline
\end{tabular}

$* * * p<0.001, * * p<0.01, * p<0.05$ 
perspectives in either of the appraisal conditions (positive and no positive) for the low shame-proneness participants. Failure to find support for the predicted beneficial effects of a third-person perspective in attenuating shame for low shame individuals also meant that hypothesis 3 predicting the lowest levels of shame among those in the low shameprone participants in the third-person perspective, positive appraisal condition was not supported.

\section{Hypothesis 4 and 5: The Combined and Separate Effects of Perspective and Appraisal on the Experience of Shame Among High Shame-Prone Participants}

A significant interaction between Appraisal and Perspective was found only for highproneness groups, $F(1,79)=9.35, \eta 2=0.10, p<0.01$. As depicted in Fig. 4, among high-shame participants in the no positive reappraisal groups, those in the third-person perspective condition $(M=7.09, \mathrm{SE}=0.53)$ reported significantly higher ratings of shame than those in the positive reappraisal condition $(M=2.89, \mathrm{SE}=0.34 ; t=6.53$, $p<0.001)$. However, it was also found that among the high shame-proneness, thirdperson perspective groups, those in the no positive reappraisal groups $(M=7.09$, SE $=0.53$ ) reported significantly higher ratings of shame than those in the first-person perspective conditions $(M=4.64, \mathrm{SE}=0.70 ; t=2.76, p<0.01$; Fig. 2$)$. No such significant differences were found between the positive reappraisal and no positive reappraisal groups assigned to the first-person perspective.

To further understand this interaction, a 2 (Appraisal) $\times 2$ (Perspective) $\times 6$ (Phase) ANCOVA was performed on the high-shame group data. This analysis yielded several significant effects, including a significant three-way interaction between Phase, Perspective, and Appraisal, $F(3.94,79)=4.77, \eta 2=0.05, p<0.001$ (see Fig. 4). Analysis of the three-way interaction revealed that the trajectory of shame ratings across the free recall (shame event) and instructed recall phases varied as a function of perspective and appraisal condition. In the third-person perspective groups, ratings of shame decreased

Shame-proneness

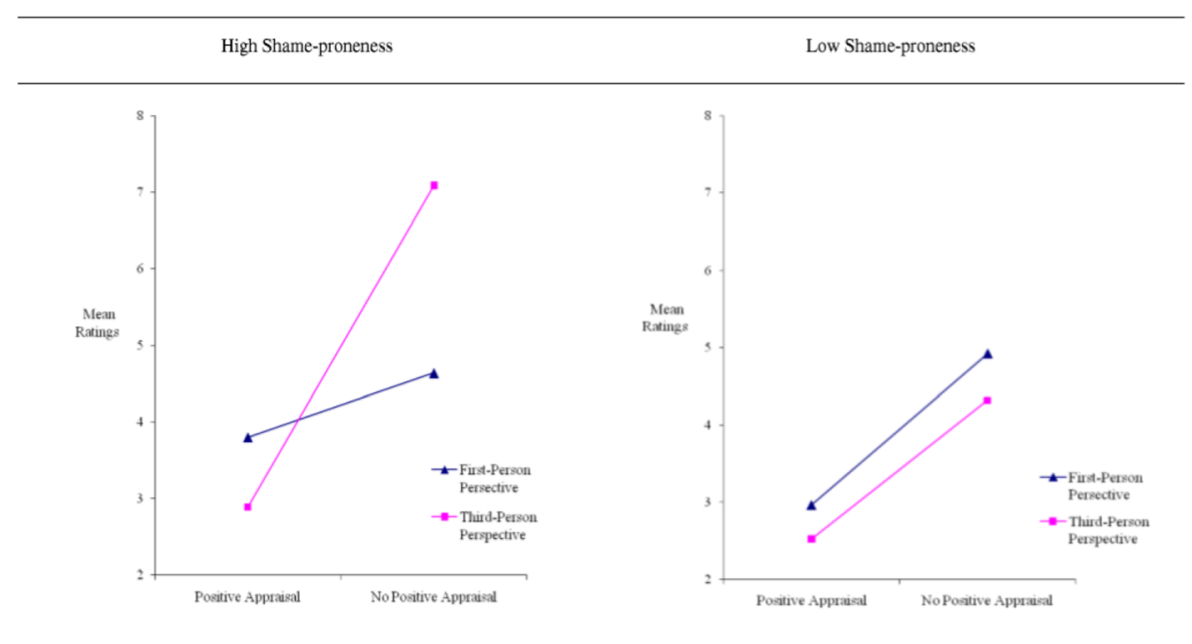

Fig. 4 Mean ratings of shame during the instructed recall phase for high and low shame-proneness groups 
between free recall $(M=5.42, \mathrm{SE}=0.65)$ and instructed recall $(M=2.89, \mathrm{SE}=0.34 ; t=$ $3.66, p<0.01$; Fig. 4$)$ in the positive reappraisal condition and increased between free recall $(M=5.59, \mathrm{SE}=0.60)$ and instructed recall $(M=7.09, \mathrm{SE}=0.33)$ in the no positive reappraisal condition ( $t=2.67, p<0.05$; Fig. 4$)$.

Thus, hypothesis 4 was upheld for high shame-prone participants in the positive appraisal condition but not for the no positive appraisal condition-in which much higher levels of shame were evident in the third-person perspective than the first-person perspective. This difference between the two perspectives was due to differences in the trajectory of shame between the free recall and instructed recall phases. Specifically, from the first-person perspective, shame ratings remained unchanged. For the thirdperson perspective condition, however, shame ratings increased between the free recall and instructed recall phases. Finally, support was found, for hypothesis 5, with high shame-prone participants reporting higher levels of shame than the low shame groups during both the free recall and instructed recall phases. The result reveal that ratings of shame remained the same between the free recall and instructed recall phases for the first-person perspective groups in both the positive and no positive reappraisal conditions (see Fig. 4). The results of this analysis are thus consistent with the view that perspective is important for high shame-prone individuals. When recalling a shameful event from a first-person perspective, positive reappraisal makes no difference, as levels of shame remain unchanged from those experienced during the initial recall of the event. In other words, a first-person perspective is neither beneficial nor detrimental.

A highly contrasted pattern is apparent when a third-person perspective is adopted, as a third-person perspective can have either beneficial or detrimental effects depending on whether positive reframing of the shameful event is encouraged. Specifically, positive reappraisal from the perspective of a third person leads to substantial reductions in the intensity of shame, whereas ruminating over the event in the absence of attempts to positively reframe it leads to a substantial increase in shame.

\section{Guilt and Other Negative Emotions}

Ratings of other negative emotions (guilt, anger, anxiety, disgust and sadness) were analysed using a 2 (Perspective) $\times 2$ (Appraisal) $\times 2$ (Shame-proneness) $\times 6$ (Phase) factorial ANCOVA in order to understand whether the effects of these emotion regulation strategies are specific to shame. As with the analyses conducted for shame, covariates included age, frequency of thinking about the shame event during rest period 1 , and frequency of thinking about the shame event during instructed recall. These other negative emotions were analysed as a composite as part of the ANCOVA.

The main effect for Shame-proneness, $F(1,203)=15.56, \eta 2=0.07, p<0.001$, was found to be due to the high shame-proneness groups $(M=2.90, \mathrm{SE}=0.13)$ reporting higher levels of negative emotions than the low shame-proneness groups $(M=2.22$, $\mathrm{SE}=0.10)$. A main effect was also found for Phase, $F(3.58,203)=2.44, \eta 2=0.01$, $p<0.05$. Post hoc analyses of the means for Phase revealed that negative emotion ratings during the free recall (shame event) phase $(M=3.38, \mathrm{SE}=0.11)$ were higher than ratings during the instructed recall phase $(M=3.01, \mathrm{SE}=0.12)$, which in turn were higher than ratings for the two rest periods $\left(M_{\text {Rest Period 1 }}=2.51, \mathrm{SE}=0.09 ; \mathrm{M}_{\text {Rest Period }}\right.$ ${ }_{2}=2.58, \mathrm{SE}=0.11 ; p$ 's $\left.<0.05\right)$. The rest period shame ratings were higher than baseline 
ratings $(M=2.21, \mathrm{SE}=0.08)$, which in turn were higher than ratings for the free recall (happy event) phase $(M=1.68, \mathrm{SE}=0.06, p$ 's $<0.05)$. This main effect was qualified by a significant interaction between Phase and Appraisal, $F(3.58,203)=3.44, \eta 2=$ $0.01, p<0.05$.

Post hoc $t$ tests of the means reveal that the no positive reappraisal groups reported higher ratings of negative emotions than the positive reappraisal groups during instructed recall $\left(M_{\text {No positive reappraisal }}=3.36, \mathrm{SE}=0.17 ; \mathrm{M}_{\text {Positive reappraisal }}=2.66, \mathrm{SE}=\right.$ $0.18 ; t=3.38, p<0.01)$ and rest period $2\left(M_{\text {No positive reappraisal }}=2.82, \mathrm{SE}=0.15 ; M_{\text {Positive }}\right.$ reappraisal $=2.33, \mathrm{SE}=0.16 ; t=2.71, p<0.01)$. Ratings of negative emotions by positive reappraisal groups during the instructed recall phase $(M=2.66, \mathrm{SE}=0.18)$ were found to be significantly lower than for the free recall (shame event) phase $(M=3.20, \mathrm{SE}=$ $0.17 ; t=4.27 ; p<0.001)$. No such differences were found for the no positive reappraisal group. A significant reduction in levels of negative emotions during rest period 2 was also found for both the positive reappraisal and no positive reappraisal groups $\left(M_{\text {Positive Reappraisal }}=2.33, \mathrm{SE}=0.16 ; \mathrm{M}_{\text {No Positive Reappraisal }}=2.82, \mathrm{SE}=0.15\right)$ compared to the instructed recall phase $\left(M_{\text {Positive Reappraisal }}=2.66, \mathrm{SE}=0.18 ; M_{\text {No Positive Reappraisal }}=\right.$ $3.36, \mathrm{SE}=0.17 ; t$ Positive Reappraisal $=3.89, p<0.001 ; t$ No Positive Reappraisal $=$ $5.07, p<0.001)$.

Overall, high shame-prone individuals reported higher levels of negative emotions than low shame-prone groups across all experimental phases. It was also found that the ratings of negative emotions varied as a function of Appraisal. In the positive reappraisal conditions, ratings of negative emotions reduced during the instructed recall phase relative to the free recall (shame event) phase. No such reduction was apparent in the no positive reappraisal condition. This difference meant that negative emotions during the instructed recall phase were higher in the no positive reappraisal conditions than in the positive reappraisal conditions. Furthermore, although negative emotions decreased for all groups during rest period 2 following the instructed recall phase, levels of negative emotion remained substantially higher for the no positive reappraisal groups during rest period 2 .

\section{Positive Emotions}

A 2 (Perspective) $\times 2$ (Appraisal) $\times 2$ (Shame-proneness $) \times 6$ (Phase) factorial ANCOVA was performed on ratings of positive emotions (happiness, pride, amusement, hope and affection) to provide a basis for comparison against the effects of these emotion regulation strategies for shame. As with the previous analyses, covariates were age and ratings of frequency of thinking about the shame event during (a) rest period 1 and (b) instructed recall. As with the previous analyses, ratings of positive emotions were analysed as a composite. In brief, reported levels of positive emotion varied in predictable ways across the various experimental phases, with all groups displaying a marked reduction in positive feelings from Baseline to the free recall and instructed recall phases and the two rest periods following these phases. Interestingly, however, a further reduction in positive emotion was evident during instructed recall for those participants who were asked to think about the shame event from the first-person perspective in the no positive reappraisal condition. In contrast, the first-person 
perspective positive reappraisal group maintained the level of positive emotion reported during the free recall phase across the instructed recall phase.

\section{Manipulation Check}

Recall that ratings of first-person and third-person perspectives adopted by participants during the experimental tasks were obtained from all eight groups during the free recall (shame event) phase and the instructed recall phase. To assess instruction compliance by the groups, the data were analysed using a 2 (Appraisal: positive reappraisal, no positive reappraisal $) \times 2$ (Perspective Condition: first-person, third-person) $\times 2$ (Shameproneness: low shame-proneness, high shame-proneness) $\times 2$ (Perspective Adopted: first-person, third-person) $\times 2$ (Phase: free recall, instructed recall) mixed factorial ANOVA with repeated measures on the last two measures.

Results revealed that in the instructed recall phase, the third-person perspective groups were more likely to view the shame event from a third-person perspective and the first-person perspective groups were more likely to view the shame event from a first-person perspective. Analyses for the within-group comparisons revealed reliable differences between the first-person perspective groups and the third-person perspective groups in the pattern of ratings for the perspective adopted across the free recall (shame event) and instructed recall phases. In brief, participants in the first-person perspective groups were more likely to view the shame event from a first-person perspective during both the free recall (shame event) and instructed recall phases. Third-person perspective groups, however, were more likely to view the shame event from a first-person perspective during the free recall (shame event) phase and more likely to view the event from a third-person perspective during the instructed recall phase. These differences indicate that the instructions designed to influence perspective taking during instructed recall were effective.

\section{Discussion}

The present research was designed to examine the separate and combined effects of two affect regulation strategies, namely positive reappraisal and perspective taking, on the regulation of feelings of shame experienced by individuals differing in shame-proneness. The major finding to emerge from this analysis was a reliable four-way interaction (i.e. Phase $\times$ Perspective $\times$ Appraisal $\times$ Shame-proneness) indicating that the pattern of shame ratings obtained across the six experimental phases differed for high and low shame-prone individuals. For low shame-prone participants, positive reappraisal led to reductions in shame during the instructed recall phase (relative to the free recall [shame event] phase), whereas no changes in shame were apparent in the no positive reappraisal groups. This difference in the pattern of shame resulted in substantially lower levels of shame in the positive reappraisal groups compared to the no positive reappraisal groups, irrespective of the perspective adopted. In contrast, perspective taking made no impact on for low-shame groups. For high shame-prone individuals, when a first-person perspective was adopted, no reduction in shame was reported in either the positive reappraisal or no positive reappraisal conditions. Adopting a third-person perspective did, however, make a marked difference for high shame groups. That is, 
positive reappraisal from the perspective of a third person led to substantial reductions in the intensity of shame among high shame-prone participants.

\section{Support for Hypotheses}

The pattern of shame results observed provides mixed support for the hypotheses generated. Hypothesis 1, which predicted lower levels of shame in the positive reappraisal condition than in the no positive reappraisal condition, should be revised in future research to account for effects of perspective and individual differences in shame-proneness. The hypothesis was supported for low-shame individuals but was only upheld for the high-shame groups adopting a third-person perspective. No reliable difference between the appraisal conditions appeared when high shame individuals viewed the shame event from their own perspective. Hypothesis 2 predicted that among low shame-prone individuals, those in the third-person perspective condition would report lower levels of shame than those in the first-person perspective condition. This hypothesis was not supported, as no differences were found between the first- and third-person perspectives in either of the appraisal conditions (positive reappraisal and no positive reappraisal). Hypothesis 3 was also not supported, as no beneficial effects of a third-person perspective in attenuating shame for low shame individuals were observed.

Similarly, hypothesis 4, which stated that there would be no differences in shame by perspective for the high-shame groups, was only partially supported. This prediction was upheld for the positive reappraisal condition but not for the no positive reappraisal condition, in which much higher levels of shame were evident in the third-person perspective than the first-person perspective. This difference between the two perspectives was due to differences in the trajectory of shame between the free recall and instructed recall phases. Specifically, for the first-person perspective condition, shame ratings remained unchanged between the two phases. For the third-person perspective condition, however, shame ratings increased between the free recall and instructed recall phases.

Finally, support was found for Hypothesis 5, which stated that high shame-prone participants would report higher levels of shame than low shame-prone participants during both the free recall and instructed recall phases. High shame-prone participants were also found to experience a greater intensity of other negative emotions than low shame-prone participants. These findings further support the validity of the TOSCA-3 (Tangney \& Dearing, 2002) in differentiating between individuals in terms of the intensity of shame experienced. As the TOSCA-3 is based on H.B. Lewis's (1987) conceptualization of shame, this finding lends further support to the idea that high shame-prone individuals engage in negative, stable, global and uncontrollable selfattributions ('I am bad') in the face of shame-eliciting stimuli and, hence, experience higher levels of shame than others (Tangney, 1995; Tangney \& Dearing, 2002).

It is important to note that there were no differences between the experimental groups with respect to the intensity of shame experienced during the recalled shame event, the recency of the event, or the frequency of having thought about or talked about the event since it occurred. Differences among the groups with respect to age, having thought about the event during rest period 1, and having thought about the event during instructed recall were controlled for in the final analyses. A manipulation check 
revealed that participants complied with instructions asking them to adopt either a firstor third-person perspective. These findings indicate that the results obtained reflect the interactive effects of the variables of interest.

\section{Combined and Separate Effects of Positive Reappraisal and Perspective Taking}

Cognitively reframing the shame experience from the perspective of an observer led to significant reductions in shame, whereas focusing on the event, without any attempt to positively reappraise it, resulted in significant increases in shame intensity. Marked differences in shame in favour of the positive reappraisal condition were apparent during instructed recall for high-shame participants adopting a third-person perspective. These findings appear to be consistent with Katzir and Eyal's (2013) findings. Interestingly, positive reappraisal from a third-person perspective was also found to be beneficial for low-shame groups, with reductions in shame reported during the instructed recall phase compared to the free recall phase. These similar results suggest that the use of positive reappraisal from the third-person perspective was beneficial in reducing shame for both high and low shame-prone individuals.

Why did the perspective adopted not have the predicted influence on the use of positive reappraisal versus no positive reappraisal among all participants? Research indicates that when adopting a first-person perspective, individuals experience relatively high levels of emotional arousal, which may then hinder the individual's ability to engage in cognitive analysis and emotion regulation (e.g. Nigro and Neisser 1983; Robinson and Swanson 1993). The third-person perspective provides individuals with increased perspective (or social distance) and the capacity to review difficulties by considering additional features of the situation, leading to appraisals that attenuate negative affect (McIsaac and Eich 2002; Robinson and Swanson 1993). Given these findings, it was expected that among low-shame groups, a first-person perspective would compromise the benefits of cognitive construal while compounding the adverse effects of not using positive appraisals. Similarly, it was expected that a third-person perspective would help alleviate the negative influence of not using positive reappraisal and further attenuate shame when used in conjunction with positive reappraisal.

\section{Implications for Low Shame-Prone Individuals}

For the low shame-prone groups, our findings revealed that no differential effects were experienced when using positive reappraisal in conjunction with a first- or third-person perspective. Because low shame-prone individuals do not possess as many cognitive vulnerabilities or the negative attributional style of high shame-prone individuals (Tangney, 1995), the use of positive reappraisal potentially represents a more powerful emotion regulation strategy than changing one's memory perspective. With low-shame individuals reporting lower levels of shame than high-shame participants, it is possible that the use of positive reappraisal on its own is effective in attenuating relatively lower levels of shame.

The finding that perspective made no difference for low-shame individuals in the no positive reappraisal condition is somewhat more difficult to explain in light of extant research on the benefits of adopting a more distant (i.e. third-person) perspective. However, no research has examined the effects of perspective taking on thoughts and 
memories specifically related to shameful experiences. Shame differs from other negative emotions in that it involves a greater focus on the self as bad or inadequate (Tangney, 1995), and it may be this aspect of shame that is influenced by perspective in ways that other negative emotions are not. Further research examining the effects of first- versus third-person perspective taking, in the absence of positive reappraisal, on thoughts about multiple negative emotions (e.g. anger, sadness, shame) may shed light on this. Interestingly, the use of positive reappraisal and the third-person perspective by low shame-prone individuals was also found to be beneficial, with lower ratings of shame reported during the instructed recall phase than during the free recall phase. Similarly, low-shame individuals benefited from maintaining a moderate level of positive emotion between these two phases when using positive reappraisal from the third-person perspective. Thus, positive reappraisal of shame experiences from a thirdperson perspective led to decreased feelings of shame for both low- and high-shame individuals, revealing it to be an effective affect regulation strategy for reducing feelings of shame, irrespective of individual differences in the propensity to experience shame.

\section{Implications for High Shame-Prone Individuals}

Turning now to the high shame-prone participants, no reliable differences were found between the first- and third-person perspective in levels of shame reported by those in the positive reappraisal condition. In other words, in the presence of encouragement to cognitively reframe the shame experienced, differences in perspective appear not to matter. However, in the absence of suggestions of positive reappraisal, levels of shame remained unchanged (relative to the free recall phase) in high-shame participants adopting a first-person perspective and increased substantially when the third-person perspective was used, leading to a marked difference in the intensity of shame between the two perspectives. How can this pattern of results be accounted for? The distinction between internal and external shame (Gilbert, 1998) is of particular relevance here. Internal shame reflects criticism and negative evaluation directed toward the self. In contrast, external shame is attributable to heightened attention to the interpersonal world, together with increased sensitivity to others' evaluations of the self and knowledge that others view the self negatively. In other words, external shame 'involves negative views of self as seen through the eye of others' (Kim et al. 2011, p. 87). It is possible that when thinking of a shame-eliciting event from one's own point of view (first-person perspective), feelings of internal shame may be triggered, while thinking about the event from the perspective of another person may trigger feelings of external shame (Kim et al. 2011). Although episodes of shame likely involve mutually reinforcing external and internal elements, external shame has been identified as a more potent source of distress, showing greater associations with depression symptoms than internal shame (Gilbert, 1998; Kim et al. 2011). The present results are clearly consistent with this conceptualization.

The greater vulnerability of high shame-prone individuals to external shame may be best explained by the characteristic mental representations of significant others or relational schemas that shame-prone individuals possess (Baldwin, 1992). Baldwin (1992) defines relational schemas as 'cognitive structures representing regularities in patterns of interpersonal relatedness' (p.g. 461) and comprise a schema of self, a 
schema for others, and an interpersonal script (Abelson, 1981) for patterns of interaction that routinely occur between the self and others. Over time, based on a person's experiences of relational interactions, the individual develops expectations about the behaviour of others (Baldwin \& Sinclair, 1996; Baldwin, 1992). High shame-prone individuals make negative attributions about themselves in response to adverse events, as well as have negative expectations of how others will respond to them (Tangney \& Dearing, 2002).

While low shame-prone individuals may expect at least some people in shameeliciting situations to view and respond to them compassionately, high shame-prone individuals are more likely to expect others to respond to them critically, with ridicule and harsh judgement (Zaslav 1998). Thus, when thinking about their shame events from a third-person perspective, without the suggestion of a positive construal, high shame-prone participants' negative relational schema may be activated. These negative mental representations can lead to painful feelings of external shame and concurrent feelings of internal shame, rumination and distress of higher intensity than that experienced by low-shame individuals or those adopting a first-person perspective (Baldwin \& Sinclair 1996; Baldwin et al. 1996; Zaslav 1998). Understanding more about the relational schemas of high shame-prone persons and their role in the maintenance or amplification of shame is a potentially important avenue for future research.

It is important to note that there were no reliable differences between the first-person and third-person perspective for the high-shame participants in the positive reappraisal groups. As mentioned earlier, this finding suggests that differences in perspective appear not to matter. However, there is other evidence to suggest that the thirdperson perspective, positive reappraisal condition may be particularly beneficial for high-shame individuals: High-shame participants in the positive reappraisal, thirdperson perspective condition reported marked decreases in shame between the free recall and instructed recall phases, whereas the positive reappraisal, first-person perspective was not associated with reduced shame. Furthermore, although differences in shame between positive reappraisal from the first- versus third-person perspective failed to reach conventional levels of statistical significance, levels of shame in the third-person perspective condition $(M=2.89)$ were lower than those in the first-person perspective condition $(M=3.80, t=1.50, p=0.14)$. This trend raises the possibility that future research with a larger sample and, in particular, with participants more extreme in their high levels of shame-proneness, may reveal a substantial and more reliable difference between these two positive reappraisal conditions.

In brief, the results of the present research clearly indicate that positive reappraisal from a third-person perspective is an effective affect regulation strategy for attenuating shame in high shame-prone individuals. This finding is particularly interesting in view of research suggesting that high shame-prone people have difficulty adopting the perspective of others (e.g. Yang et al. 2010). The results observed here are not entirely consistent with this conclusion: instructions to take the perspective of another in the context of positive reappraisal led to decreased shame, while such instructions in the absence of positive reappraisal led to increased shame. Moreover, this difference cannot only be attributed to appraisal differences, since a similar pattern was not apparent across the two appraisal conditions from a first-person perspective. The overall pattern of results clearly indicates that high shame-prone people are capable of adopting the perspective of another; whether they often hold back from doing so is another question. 


\section{Limitations and Future Research}

This study has limitations. Results are based on university students who were, on average, 21 years of age and whose life experiences may be somewhat limited. Although some research suggests that university students' experiences with stressful life events are comparable to those of individuals in the general population (e.g. Cusack et al. 2019), it is unclear whether the present results can be generalized to older populations, given numerous other differences between college students and others. A longitudinal study conducted by Orth et al. (2006) on the trajectories of shame, guilt and pride across the lifespan found that shame levels were highest in adolescence and early adulthood and decreased in midlife. Given this, it is encouraging that the intervention of positive reappraisal from the third-person perspective was successful in attenuating shame among a sample consisting primarily of young adults likely to be experiencing relatively high levels of shame. Future research should extend these findings to other populations, especially those presenting clinically.

A second limitation is that the interventions used in this study were brief, comprising one trial lasting for $2 \mathrm{~min}$. Despite this limitation, substantial and robust beneficial effects were detected when encouraging participants to think about their shame experiences in a different and more positive light. Furthermore, one can speculate that longer interventions (either longer trials, more trials or both) would have even more substantial and durable effects. And important direction for future research is investigating the effects of prolonged and more intensive interventions designed to attenuate shame. Comparative studies of the effectiveness of positive reappraisal using a thirdperson perspective with other interventions such as mindfulness (Gilbert and Procter 2006) and emotion-focused therapy (Greenberg 2004) would also be of value.

\section{Conclusion}

This study revealed that individual differences in propensity to experience shame influenced the efficacy of two emotion regulation strategies, perspective taking and positive reappraisal. Perspective was found to have little impact on low shame-prone individuals. In marked contrast to this, the trajectory of shame ratings for high-shame individuals varied as a function of perspective and appraisal. When a first-person perspective was used, levels of shame remained unchanged in both the positive reappraisal and rumination, no positive reappraisal conditions, indicating that no beneficial effects resulted from positively reframing the shame event from one's own viewpoint. However, when a third-person perspective was adopted, shame decreased in the appraisal condition but increased in the no positive reappraisal condition. Thus, therapeutic interventions aimed at reducing shame may need to take into consideration individual differences in shame-proneness when supporting clients' use of the cognitive strategies of perspective taking and positive reappraisal.

\section{Compliance with Ethical Standards}

Ethics approval to conduct the study was received from the Griffith University Human Research Ethics Committee (Reference Number: PSY/03/08/HREC). 
Conflict of Interest There authors declare that there are no conflicts of interests.

\section{Appendix. Instructions provided to participants as part of the mood induction in the study}

In the cognitive appraisal, first-person perspective condition, participants were given the following instructions:

"Now I'd like you to think about the shame event again. This time, I'd like you to visualize the event from the same visual perspective that you originally had; in other words, looking out at your surroundings through your own eyes, seeing what you saw then. As you think about the event, imagine that you want the best possible outcome for yourself. Focus on how you might frame or interpret the shame event with your own best interests in mind and find the good that could come from it. To help you do this, consider your answers to the following questions (you will answer these questions later in the study).

1. Can you see where the event took place?

2. Can you see any furniture or trees around you?

3. Can you see any colours around you?

4. Can you see anyone else?

5. If so, can you see what they are wearing?"

In the cognitive appraisal, third-person perspective condition, participants were given the following instructions:

"Now I'd like you to think about the shame event again. This time, I'd like you to visualize the event from the perspective of a third party or an observer, someone who was not directly involved in the event. Imagine this observer to be someone who wants the best possible outcome for you and has your best interests in mind. As you think about the event, focus on how this observer might frame or interpret the shame event and find the good that could come from it.

To help you do this, consider your answers to the following questions (you will answer these questions later in the study).

1. Can you see what you are wearing?

2. Can you see what you are doing?

3. Can you see what your facial expression is?

4. Can you see what hairstyle you have?

5. Can you see whether you are standing or sitting?"

In the no cognitive appraisal, first-person perspective condition, participants were given the following instructions:

"Now I'd like you to think about the shame event again. This time, I'd like you to visualize the event from the same visual perspective that you originally had; in other words, looking out at your surroundings through your own eyes, seeing what you saw then. As you think about the event, turn it over and over in your mind. Focus on those things that initially made you feel and respond the way you did.

To help you do this, consider your answers to the following questions (you will answer these questions later in the study).

1. Can you see where the event took place?

2. Can you see any furniture or trees around you? 
3. Can you see any colours around you?

4. Can you see anyone else?

5. If so, can you see what they are wearing?"

In the no cognitive appraisal, third-person perspective condition, participants were given the following instructions:

"Now I'd like you to think about the shame event again. This time, I'd like you to visualize the event from the perspective of a third party or an observer, someone who was not directly involved in the event. As you think about the event, turn the event over and over in your mind. Focus on those things that initially made you feel and respond the way you did.

To help you do this, consider your answers to the following questions (you will answer these questions later in the study).

1. Can you see what you are wearing?

2. Can you see what you are doing?

3. Can you see what your facial expression is?

4. Can you see what hairstyle you have?

5. Can you see whether you are standing or sitting?"

\section{References}

Abelson, R. P. (1981). Psychological status of the script concept. American psychologist, 36(7), 715.

Baldwin, M. W. (1992). Relational schemas and the processing of social information. Psychological bulletin, $112(3), 461$.

Baldwin, M. W., Keelan, J. P. R., Fehr, B., Enns, V., \& Koh-Rangarajoo, E. (1996). Social-cognitive conceptualization of attachment working models: availability and accessibility effects. Journal of Personality and Social Psychology, 71(1), 94-109. https://doi.org/10.1037/0022-3514.71.1.94.

Beck, A. T. (2005). The current state of cognitive therapy: a 40-year retrospective. Archives of General Psychiatry, 62(9), 953-959.

Brown, K. W., \& Ryan, R. M. (2003). The benefits of being present: mindfulness and its role in psychological well-being. Journal of Personality and Social Psychology, 84(4), 822-848. https://doi.org/10.1037/00223514.84.4.822.

Castilho, P., Pinto-Gouveia, J., \& Duarte, J. (2017). Two forms of self-criticism mediate differently the shame-psychopathological symptoms link. Psychology and Psychotherapy: Theory, Research and Practice, 90(1), 44-54. https://doi.org/10.1111/papt.12094.

Cunningham, K. C., LoSavio, S. T., Dennis, P. A., Farmer, C., Clancy, C. P., Hertzberg, M. A., ... Beckham, J. C. (2019). Shame as a mediator between posttraumatic stress disorder symptoms and suicidal ideation among veterans. Journal of Affective Disorders, 243(June 2018), 216-219. https://doi.org/10.1016/j. jad.2018.09.040.

Cusack, S. E., Hicks, T. A., Bourdon, J., Sheerin, C. M., Overstreet, C. M., Kendler, K. S., ..., Amstadter, A. B. (2019). Prevalence and predictors of PTSD among a college sample. Journal of American College Health, 67(2), 123-131. https://doi.org/10.1080/07448481.2018.1462824.

Duarte, C., \& Pinto-Gouveia, J. (2017). Can self-reassurance buffer against the impact of bullying? Effects on body shame and disordered eating in adolescence. Journal of Child and Family Studies, 26(4), 998-1006. https://doi.org/10.1007/s10826-016-0624-1.

Ehring, T., Tuschen-Caffier, B., Schnülle, J., Fischer, S., \& Gross, J. J. (2010). Emotion regulation and vulnerability to depression: spontaneous versus instructed use of emotion suppression and reappraisal. Emotion, 10(4), 563-572. https://doi.org/10.1037/a0019010.

Fergus, T. A., Valentiner, D. P., McGrath, P. B., \& Jencius, S. (2010). Shame- and guilt-proneness: relationships with anxiety disorder symptoms in a clinical sample. Journal of Anxiety Disorders, 24(8), 811-815. https://doi.org/10.1016/j.janxdis.2010.06.002.

Ferguson, T. J., \& Crowley, S. L. (1997). Measure for measure: A multitrait-multimethod analysis of guilt and shame. Journal of personality assessment, 69(2), 425-441. 
Gilbert, P. (1998). What is shame? Some core issues and controversies. In P. Gilbert \& B. Andrews (Eds.), Series in affective science. Shame: Interpersonal behavior, psychopathology, and culture (pp. 3-38). Oxford University Press.

Gilbert, P., \& Procter, S. (2006). Compassionate mind training for people with high shame and self-criticism: overview and pilot study of a group therapy approach. Clinical Psychology \& Psychotherapy, 13(6), 353379. https://doi.org/10.1002/cpp.507.

Gilbert, P. (2010). An introduction to compassion focused therapy in cognitive behavior therapy. International Journal of Cognitive Therapy, 3(2), 97-112.

Greenberg, L. S. (2004). Emotion - focused Therapy. 16, 3-16.

Gross, J. J. (1998). The emerging field of emotion regulation: An integrative review. Review of general psychology, 2(3), 271-299.

Jylhä, P., \& Isometsä, E. (2006). The relationship of neuroticism and extraversion to symptoms of anxiety and depression in the general population. Depression and anxiety, 23(5), 281-289.

Kabat-Zinn, J., Massion, A. O., Kristeller, J., Peterson, L. G., \& Al, E. (1992). No title. American Journal of Psychiatry, 149-936.

Katzir, M., \& Eyal, T. (2013). When stepping outside the self is not enough: a self-distanced perspective reduces the experience of basic but not of self-conscious emotions. Journal of Experimental Social Psychology, 49(6), 1089-1092. https://doi.org/10.1016/j.jesp.2013.07.006.

Kim, S., Thibodeau, R., \& Jorgensen, R. S. (2011). Shame, guilt, and depressive symptoms: a meta-analytic review. Psychological Bulletin, 137(1), 68-96. https://doi.org/10.1037/a0021466.

Kross, E., \& Ayduk, O. (2017). Social distancing: theory, research, and current directions. In Advances in Experimental Social Psychology (1st ed., Vol. 55). https://doi.org/10.1016/bs.aesp.2016.10.002.

Kross, E., \& Ayduk, O. (2008). Facilitating adaptive emotional analysis: distinguishing distanced-analysis of depressive experiences from immersed-analysis and distraction. Personality and Social Psychology Bulletin, 34(7), 924-938. https://doi.org/10.1177/0146167208315938.

Kross, E., Ayduk, O., \& Mischel, W. (2005). When asking "why" does not hurt distinguishing rumination from reflective processing of negative emotions. Psychological science, 16(9), 709-715.

Lazarus, R. S., \& Folkman, S. (1984). Stress, appraisal, and coping. Springer publishing company.

Levine, L. J., Schmidt, S., Kang, H. S., \& Tinti, C. (2012). Remembering the silver lining: reappraisal and positive bias in memory for emotion. Cognition \& Emotion, 26(5), 871-884. https://doi.org/10.1080 /02699931.2011.625403.

Lewis, H. B. (1987). The many faces of shame. Routledge.

Libby, L. K., \& Eibach, R. P. (2002). Looking back in time: self-concept change affects visual perspective in autobiographical memory. Journal of personality and social psychology, 82(2), 167.

Libby, L. K., Eibach, R. P., \& Gilovich, T. (2005). Here's looking at me: the effect of memory perspective on assessments of personal change. Journal of Personality and Social Psychology, 88(1), 50-62. https://doi. org/10.1037/0022-3514.88.1.50.

Linehan, M. M. (1993). Skills training manual for treating borderline personality disorder. Guilford Press.

McIsaac, H. K., \& Eich, E. (2002). Vantage point in episodic memory. Psychonomic Bulletin \& Review, 9(1), 146-150. https://doi.org/10.3758/BF03196271.

Mosewich, A. D., Kowalski, K. C., Sabiston, C. M., Sedgwick, W. A., \& Tracy, J. L. (2011). Selfcompassion: a potential resource for young women athletes. Journal of Sport and Exercise Psychology, 33(1), 103-123. https://doi.org/10.1123/jsep.33.1.103.

Neff, K. (2003). Self-compassion: an alternative conceptualization of a healthy attitude toward oneself. Self and Identity, 2(2), 85-101. https://doi.org/10.1080/15298860309032.

Nigro, G., \& Neisser, U. (1983). Point of view in personal memories. Cognitive Psychology, 15(4), 467-482.

Ochsner, K. N., Silvers, J. A., \& Buhle, J. T. (2012). Review and evolving model of the cognitive control of emotion. Annals of the New York Academy of Sciences, 1251, E1-E24. https://doi.org/10.1111/j.17496632.2012.06751.x.

Orth, U., Berking, M., \& Burkhardt, S. (2006). Self-conscious emotions and depression: rumination explains why shame but not guilt is maladaptive. Personality and Social Psychology Bulletin, 32(12), 1608-1619. https://doi.org/10.1177/0146167206292958.

Orth, U., Robins, R. W., \& Soto, C. J. (2010). Tracking the trajectory of shame, guilt, and pride across the life span. Journal of personality and social psychology, 99(6), 1061.

Penley, J. A., Tomaka, J., \& Wiebe, J. S. (2002). The association of coping to physical and psychological health outcomes: a meta-analytic review. Journal of Behavioral Medicine, 25(6), 551-603. https://doi. org/10.1023/A:1020641400589.

Potter-Efron, R., \& Bruce, C. (2014). Shame, guilt, and alcoholism: treatment issues in clinical practice. 
Quiles, Z. N., \& Bybee, J. (1997). Chronic and predispositional guilt: Relations to mental health, prosocial behavior, and religiosity. Journal of personality assessment, 69(1), 104-126.

Ray, R. D., Wilhelm, F. H., \& Gross, J. J. (2008). All in the mind's eye? Anger rumination and reappraisal. Journal of Personality and Social Psychology, 94(1), 133-145. https://doi.org/10.1037/00223514.94.1.133.

Robinson, J. A., \& Swanson, K. L. (1993). Field and observer modes of remembering. Memory, 1(3), 169184.

Rood, L., Roelofs, J., Bögels, S. M., \& Arntz, A. (2012). The effects of experimentally induced rumination, positive reappraisal, acceptance, and distancing when thinking about a stressful event on affect states in adolescents. Journal of Abnormal Child Psychology, 40(1), 73-84. https://doi.org/10.1007/s10802-0119544-0.

Shanahan, S., Jones, J., \& Thomas-Peter, B. (2011). Are you looking at me, or am I? Anger, aggression, shame and self-worth in violent individuals. Journal of Rational-Emotive \& Cognitive-Behavior Therapy, 29(2), 77-91. https://doi.org/10.1007/s10942-009-0105-1.

Sheppes, G., Suri, G., \& Gross, J. J. (2015). Emotion regulation and psychopathology. Annual Review of Clinical Psychology, 11, 379-405. https://doi.org/10.1146/annurev-clinpsy-032814-112739.

Silvers, J. A., Weber, J., Wager, T. D., \& Ochsner, K. N. (2015). Bad and worse: neural systems underlying reappraisal of high-and low-intensity negative emotions. Social Cognitive and Affective Neuroscience, 10(2), 172-179. https://doi.org/10.1093/scan/nsu043.

Sloan, E., Hall, K., Moulding, R., Bryce, S., Mildred, H., \& Staiger, P. K. (2017). Emotion regulation as a transdiagnostic treatment construct across anxiety, depression, substance, eating and borderline personality disorders: a systematic review. Clinical Psychology Review, 57(September), 141-163. https://doi. org/10.1016/j.cpr.2017.09.002.

Stuewig, J., Tangney, J. P., Kendall, S., Folk, J. B., Meyer, C. R., \& Dearing, R. L. (2015). Children's proneness to shame and guilt predict risky and illegal behaviors in young adulthood. Child Psychiatry and Human Development, 46(2), 217-227. https://doi.org/10.1007/s10578-014-0467-1.

Tabachnick, B. G., \& Fidell, L. S. (2007). Using multivariate statistics (5th ed.). Allyn \& Bacon/Pearson Education.

Tangney, J. P., \& Dearing, R. L. (2002). Emotions and social behavior. In Shame and guilt. Guilford Press.

Tangney, J. P., \& Dearing, R. L. (2003). Shame and guilt. Guilford Press.

Tangney, J. P. (1990). Assessing individual differences in proneness to shame and guilt: Development of SelfConscious Affect and Attribution Inventory. Journal of personality and social psychology, 59(1), 102.

Tangney, J. P. (1991). Moral affect: The good, the bad, and the ugly. Journal of Personality and Social Psychology, 61(4), 598-596.

Tangney, J. P., Wagner, P., \& Gramzow, R. (1992). Proneness to shame, proneness to guilt, and psychopathology. Journal of Abnormal Psychology, 101(3), 469-478. https://doi.org/10.1037/0021-843 X.101.3.469.

Tangney, J. P. (1995). Recent advances in the empirical study of shame and guilt. American Behavioral Scientist, 38(8), 1132-1145.

Tangney, J. P. (1996). Conceptual and methodological issues in the assessment of shame and guilt. Behaviour research and therapy, 34(9), 741-754.

Teasdale, J. D., Segal, Z. V., Williams, J. M. G., Ridgewaya, V. A., Soulsby, J. M., \& Lau, M. A. (2000). Prevention of relapse/recurrence in major depression by mindfulness-based cognitive therapy. Journal of Consulting and Clinical Psychology, 68(4), 615-623. https://doi.org/10.1037/0022-006X.68.4.615.

Tracy, J. L., Robins, R. W., \& Tangney, J. P. (2007). The self-conscious emotions: theory and research. Guilford Press.

Webb, T. L., Miles, E., \& Sheeran, P. (2012). Dealing with feeling: a meta-analysis of the effectiveness of strategies derived from the process model of emotion regulation. Psychological Bulletin, 138(4), 775808. https://doi.org/10.1037/a0027600.

Whittle, S., Liu, K., Bastin, C., Harrison, B. J., \& Davey, C. G. (2016). Neurodevelopmental correlates of proneness to guilt and shame in adolescence and early adulthood. Developmental Cognitive Neuroscience, 19, 51-57. https://doi.org/10.1016/j.dcn.2016.02.001.

Wiklander, M., Samuelsson, M., Jokinen, J., Nilsonne, Å, Wilczek, A., Rylander, G., \& Åsberg, M. (2012). Shame-proneness in attempted suicide patients BMC Psychiatry, 12. https://doi.org/10.1186/1471-244X12-50.

Woods, H., \& Proeve, M. (2014). Relationships of mindfulness, self-compassion, and meditation experience with shame-proneness. Journal of Cognitive Psychotherapy, 28(1), 20-34. 
Yang, M. L., Yang, C. C., \& Chiou, W. B. (2010). When guilt leads to other orientation and shame leads to egocentric self-focus: effects of differential priming of negative affects on perspective taking. Social Behavior and Personality, 38(5), 605-614. https://doi.org/10.2224/sbp.2010.38.5.605.

Zaslav, M. R. (1998). Shame-related states of mind in psychotherapy. The Journal of Psychotherapy Practice and Research, 7(2), 154-166.

Publisher's Note Springer Nature remains neutral with regard to jurisdictional claims in published maps and institutional affiliations. 